\title{
A protective allergy vaccine based on CpG- and protamine-containing PLGA microparticles
}

\section{Journal Article}

\section{Author(s):}

Martínez Gómez, Julia M.; Fischer, Stefan; Csaba, Noèmi S.; Kündig, Thomas M.; Merkle, Hans P.; Gander, Bruno A.; Johansen, Pål

\section{Publication date:}

2007

\section{Permanent link:}

https://doi.org/10.3929/ethz-b-000003702

\section{Rights / license:}

In Copyright - Non-Commercial Use Permitted

\section{Originally published in:}

Pharmaceutical Research 24(10), https://doi.org/10.1007/s11095-007-9318-0 


\title{
A Protective Allergy Vaccine Based on CpG- and Protamine-Containing PLGA Microparticles
}

\author{
Julia M. Martínez Gómez, ${ }^{1}$ Stefan Fischer, ${ }^{2}$ Noèmi Csaba, ${ }^{2}$ Thomas M. Kündig, ${ }^{1}$ Hans P. Merkle, ${ }^{2}$ \\ Bruno Gander, ${ }^{2}$ and Pål Johansen ${ }^{1,3}$
}

Received February 8, 2007; accepted April 16, 2007; published online May 31, 2007

\begin{abstract}
Purpose. Allergen-specific immunotherapy (SIT) requires dozens of subcutaneous injections over 3 to 5 years in order to control IgE-mediated hypersensitivity, which is a T-helper 2 (Th2)-associated pathology. This study investigates the use of poly(lactide-co-glycolide) (PLGA) microparticles combined with immunostimulatory oligodeoxynucleotide $(\mathrm{CpG})$, as well as protamine in SIT.

Materials and Methods. We prepared microparticle formulations with the major allergen of bee venom, phospholipase A2 (PLA2), and analyzed the effect of co-encapsulated or admixed CpG in both naïve and bee venom allergic mice.

Results. Mice immunized with microparticles containing only PLA2 induced weak antibody responses. In contrast, the combination with $\mathrm{CpG}$ resulted in strong PLA2-specific antibody responses. The presence of $\mathrm{CpG}$ was required for the induction of the Th1-associated isotype IgG2a, and the titers of $\operatorname{IgG} 2 \mathrm{a}$ in sensitized mice correlated with a better protection against an allergen challenge. The effect of $\mathrm{CpG}$ was further strengthened when protamine was co-encapsulated for complexation of $\mathrm{CpG}$.

Conclusions. This study shows that allergen-specific immunotherapy with a PLGA-based allergendelivery system in combination with $\mathrm{CpG}$ enhanced the induction of protective IgG2a immune responses. This may improve SIT compliance and shorten its duration.
\end{abstract}

KEY WORDS: adjuvants; allergy; CpG; immunotherapy; PLGA microspheres; vaccine delivery.

\section{INTRODUCTION}

Approximately $20 \%$ of the population in developed countries suffers from IgE-mediated type-I hypersensitivity. The clinical manifestations of this type of allergy are rhinoconjunctivitis, asthma or even life-threatening anaphylactic reactions. These symptoms are all initiated by the degranulation of mast cells and basophils when their surface-bound IgE molecules are cross-linked through the binding of the allergen. Although symptomatic treatments are available, the only treatment with long-lasting effect for allergic patients is subcutaneous allergen-specific immunotherapy (SIT). During SIT, gradually increasing doses of the allergen are injected subcutaneously. This shifts the immune response against the allergen from a predominantly Th2-type response ( $\mathrm{IgE}$ and IL-4) towards a Th1-like immune response (IgG and IFN- $\gamma$ ).

Electronic supplementary material The online version of this article (doi: 10.1007/s11095-007-9318-0) contains supplementary material, which is available to authorized users.

\footnotetext{
${ }^{1}$ Unit for Experimental Immunotherapy, Department of Dermatology, University Hospital Zurich, Gloriastrasse 31, 8091, Zurich, Switzerland.

${ }^{2}$ Drug Delivery and Formulation, Institute of Pharmaceutical Sciences, ETH Zurich, Zurich, Switzerland.

${ }^{3}$ To whom correspondence should be addressed.e-mail:paljohansen@ usz.ch
}

The risk of allergic side effects is currently a major disadvantage of SIT. This has motivated the study of safer allergens such as oligopeptides derived from allergens, or recombinant proteins with reduced IgE-binding capacity (1-3). A second significant disadvantage of SIT is the high cost with a total of 30-80 injections administered over years (4). A simplified SIT with a reduced number of injections would, therefore, be highly advantageous, as it would improve patient compliance and provide socioeconomic benefits. The most frequently common adjuvants in SIT are aluminum salts, being known to favor Th2 responses (including IgE production). Aluminum salts can cause local granuloma formation at the injection site, but otherwise have a good safety record in SIT. Nevertheless, many efforts are directed towards the use of new adjuvants that favor Th1 responses (5).

Biodegradable materials such as poly(lactide-co-glycolide) (PLGA) represent a potential alternative for controlled delivery of allergens in SIT (6). PLGA preparations can deliver proteins over prolonged periods of time and induce protective immunity after a single subcutaneous injection $(7,8)$. In addition, they may also comprise adjuvants or other immune-regulating compounds, e.g. Th1-triggering compounds.

Major candidate adjuvants that shift the immune responses towards Th1 are derived from pathogens. The so-called pathogen-associated molecular patterns (PAMPs) are recognized by receptors (Toll-like receptors, TLRs) on antigen presenting cells (APCs) (9). TLR binding may activate nuclear factor- $\mathrm{kB}$, which directs the secretion of cytokines, chemokines and co-stimulatory molecules important for efficient Th1 immune responses. 
Bacterial DNA containing cytosine-guanine rich immunostimulatory sequences $(\mathrm{CpG})$ have been recognized to bind to TLR-9 and to trigger strong Th1 responses $(10,11)$.

In this study, we tested PLGA microparticles in combination with $\mathrm{CpG}$ for their use in subcutaneous SIT against the major bee venom allergen phospholipase A2 (PLA2). In mice, isotype switching to IgG2a strongly depends on Th1 CD4 T cell help. Therefore, the capacity of a vaccine to trigger IgG2a antibodies was used as an important indicator for the screening of appropriate formulations. We found that $\mathrm{CpG}$ strongly enhanced the immune response and was a prerequisite for the induction of $\mathrm{IgG} 2 \mathrm{a}$ antibody responses. This effect was more pronounced when the $\mathrm{CpG}$ was co-encapsulated rather than admixed to PLA2-containing MP. The best prophylactic and therapeutic immune responses were obtained with PLGA preparations that contained both co-encapsulated $\mathrm{CpG}$ and protamine.

\section{MATERIALS AND METHODS}

\section{Materials}

Purified phospholipase $\mathrm{A}_{2}$ (PLA2) from bee venom was purchased from Sigma-Aldrich (Buchs, Switzerland). Bee venom extract from ALK-Abelló was purchased through Trimedal (Bruttisellen, Switzerland). Aluminum hydroxide (Alhydrogel 2\%) was purchased from Brenntag Biosector (Fredrikssund, Denmark), and phosphorothioate-modified CpG oligodeoxynucleotide 1668 pt (5'-TCC-ATG-ACGTTC-CCT-GAC-GTT-3') was synthesized by Microsynth (Balgach, Switzerland). We used a $35 \mathrm{kDa}$ poly(lactide-coglycolide) (PLGA 50:50) with uncapped end-groups (Resomer RG503H) from Boehringer-Ingelheim (Ingelheim, Germany). Salmine sulfate from salmon sperm (protamine sulfate with four arginine residues at the C-terminus) and poly(vinylalcohol) (PVA, Mowiol 4-88) were obtained from Fluka (Buchs, Switzerland).

\section{Microparticle Preparation}

PLGA MP were made by microextrusion-based w/o/wsolvent extraction using a static multilamination type micromixer (Institut für Mikrotechnik Mainz GmbH, Mainz, Germany), as previously described (12), with slight modifications. Three different formulations were prepared. For one formulation, $2 \mathrm{mg}$ of PLA2 were dissolved in $100 \mu \mathrm{l}$ water and emulsified by ultrasonication with $7 \mathrm{ml}$ PLGA dissolved in dichloromethane $(5 \%, w / w)$. For the others either $4 \mathrm{mg}$ PLA2 or a mixture of $4 \mathrm{mg}$ PLA 2 and $8 \mathrm{mg}$ protamine were dissolved in $1.6 \mathrm{ml}$ water containing $1.6 \mu \mathrm{mol} \mathrm{CpG}$; this aqueous phase was emulsified with $12 \mathrm{ml}$ of a $5 \%$ PLGA solution in dichloromethane. After extrusion in the micromixer, the suspension of MP was collected in a borosilicate glass beaker containing an aqueous solution of $0.5 \%(\mathrm{w} / \mathrm{w})$ PVA for solvent extraction. The particles were gently stirred using a magnetic rod and kept in a laminar air flow for $30 \mathrm{~min}$ for further solvent removal and hardening of the particles. Finally, the particles were collected on a $0.8 \mu \mathrm{m}$ pore-sized mixed cellulose ester membrane filter (Schleicher \& Schuell, Dassel, Germany) and dried at 20 mbar and room temperature for $24 \mathrm{~h}$.

\section{Particle Size Determination}

Microparticle size distributions were determined by laser diffraction using a Mastersizer X (Malvern Instrument, Malvern, UK) after suspending approximately $1 \mathrm{mg}$ of dried MP in distilled water or in an aqueous solution of $1 \%$ lecithin. The average cumulative undersize distributions $\left(\mathrm{D}_{10}\right.$, $\mathrm{D}_{50}$ and $\mathrm{D}_{90}$ ) were determined on a volume basis.

\section{Zeta Potential Measurements}

The surface charge of the MP was determined by zeta potential measurement using a Zetasizer 3000 HSA from Malvern Instrument (Malvern, UK). Duplicates of approximately $0.2 \mathrm{mg}$ of dried MP were re-suspended in $2 \mathrm{ml}$ of a solution of $1 \mathrm{mM} \mathrm{KCl}$ ( $\mathrm{pH}$ 7.6). Alternatively, the MP were re-suspended in $1 \%$ lecithin and then diluted with $2 \mathrm{ml}$ of 1 $\mathrm{mM} \mathrm{KCl}$. Mean values of zeta potential were calculated from triplicates of each sample.

\section{Determination of Allergen Content and Integrity in the Microparticles}

The extraction of allergen from the MP for the analysis of its content and integrity was undertaken as previously described (13). Triplicates of approx. $7 \mathrm{mg}$ particles were dissolved in 0.5 $\mathrm{ml}$ chloroform by vortexing for $3 \mathrm{~min}$. PLA2 was then extracted from the organic phase by mixing with $0.2 \mathrm{ml}$ Tris$\mathrm{HCl}$ buffer and subsequent centrifugation at 3,000 rpm for 3 min. The PLA 2 concentration in the aqueous supernatant was analyzed by an ELISA inhibition assay. In detail, $60 \mu \mathrm{l}$ of the Tris- $\mathrm{HCl}$ phase containing the extracted PLA2 were mixed in a 96-well plate with $60 \mu \mathrm{l}$ of diluted (1:25) human anti-PLA2 serum in phosphate-buffered saline containing $0.05 \%$ Tween 20 and $2.5 \%$ skimmed dry milk (PBSTM). In parallel, twofold dilutions of PLA2 were mixed with sensitized serum, and established as a standard for quantification. Positive (only serum) and negative (only PBSTM) controls were also included. After $2 \mathrm{~h}$ of incubation at $37^{\circ} \mathrm{C}, 100 \mu \mathrm{l}$ of each sample were transferred to an ELISA plate that was precoated with $5 \mu \mathrm{g} / \mathrm{ml}$ PLA 2 at $4^{\circ} \mathrm{C}$ overnight and subsequently blocked with PBSTM at room temperature for $1 \mathrm{~h}$. The samples were then incubated at $37^{\circ} \mathrm{C}$ for $2 \mathrm{~h}$. Subsequently, the plate was washed and incubated with $100 \mu \mathrm{l}$ of a 1:1,000 dilution of horseradish peroxidase-conjugated anti-human IgG (BD Biosciences Pharmingen, San Diego, CA) at room temperature for $1 \mathrm{~h}$. The plate was washed and developed with $100 \mu \mathrm{l}$ of the enzyme substrate 2,2'-azino-bis(3-ethylbenzothiazoline-6-sulphonic acid) diammonium salt (SigmaAldrich) in $1 \mathrm{M}$ sodium dihydrogen phosphate. After $30 \mathrm{~min}$, the absorption was read at $405 \mathrm{~nm}$. The loading efficiency of PLA2 in the MP was calculated relative to the theoretical maximum loading value.

To assess the integrity of the allergen during MP preparation and storage, PLA2 from the various MP formulations was extracted with chloroform (as described above), loaded under reduced conditions on SDS-PAGE and run at $180 \mathrm{~V}$ for $50 \mathrm{~min}$. Following electrophoresis, the gel was stained with the silver-staining method as previously described (14). 


\section{In vitro Release of PLA2}

Accurately weighed PLA2-loaded MP (approx. $20 \mathrm{mg}$ ) were dissolved in $3.4 \mathrm{ml}$ PBS containing $0.2 \%$ BSA and incubated in a shaker at $37^{\circ} \mathrm{C}$ for 63 days. At different time points, the samples were centrifuged at $3,500 \mathrm{rpm}$ for 10 min. Aliquots of the supernatants were analyzed by inhibition ELISA to quantify the released PLA2. The dissolution medium was replaced with fresh PBS/BSA after each sampling.

\section{Immunization of Mice}

In a preliminary set of experiments, the dose of PLA2 contained in PLGA MP necessary to induce solid immune responses was determined. For dose finding, mice were immunized twice at an interval of 28 days with MP formulations (MP-PLA2, MP-PLA2-CpG-protamine) containing either 1 or $5 \mu \mathrm{g}$ of PLA2, or with $1 \mu \mathrm{g}$ of PLA2 adsorbed on aluminum hydroxide. Blood was collected on days 28,56 and 84 . The sera were frozen and kept at $-20^{\circ} \mathrm{C}$ until analyzed by ELISA.

The immunogenicity of PLA2-containing PLGA formulations was tested in 6-10 week old female CBA/J mice. Mice were primed with $1 \mu \mathrm{g}$ PLA2 entrapped in the different PLGA formulations (Table 1). Prior to injection, the MP were re-suspended using a $1 \%$ aqueous lecithin solution (Epikuron 200, Degussa, Hamburg, Germany) as a wetting agent and injection vehicle. For the MP-PLA2 + $\mathrm{CpG}$ formulation, $3.1 \mathrm{nmol} \mathrm{CpG}$ per dose was admixed to the MP-PLA2 prior to injection. As a reference, one group of mice received the same amount of PLA2 adsorbed for $1 \mathrm{~h}$ to $0.9 \mathrm{mg}$ aluminum hydroxide (PLA2 + aluminum hydroxide). Approximately $95 \%$ of the PLA2 was adsorbed to aluminum hydroxide (data not shown). All mice were boosted with the same regime after 28 days. Serum was prepared from clotted blood taken on days 28,55 and 84 and frozen at $-20^{\circ} \mathrm{C}$ until analyzed by ELISA.

To evaluate the therapeutic potential of PLA2-containing preparations in allergic mice, the animals were sensitized by six weekly intraperitoneal injections of $0.3 \mu \mathrm{g}$ bee venom allergen extract adsorbed on $1 \mathrm{mg}$ aluminum hydroxide in PBS (Fig. 1). Three weeks later (time point 0), desensitization (SIT) was initiated with different MP preparations containing $1 \mu \mathrm{g}$ PLA2 or, alternatively, $5 \mu \mathrm{g}$ PLA2 adsorbed on aluminum hydroxide. The treatment was repeated after 28 days with the same dose and, after 111 days, with $5 \mu \mathrm{g}$ PLA2 in all formulations (MP and aluminum hydroxide). Blood was taken on days $0,28,55,111$ and 139 after the first SIT injection. The sera were frozen and kept at $-20^{\circ} \mathrm{C}$ until analyzed by ELISA. For induction of anaphylactic responses, immunized mice were challenged intraperitoneally with $15 \mu \mathrm{g}$ PLA2 in saline, and the rectal temperature was measured with a calibrated digital thermometer before and $30 \mathrm{~min}$ after the challenge. All animal experiments were performed according to the guidelines of the veterinary authorities of the Canton of Zurich.

\section{Antibody Determination by Enzyme-linked Immunosorbent Assay}

For detection of PLA2 antibodies, microtitre 96-well plates (Nunc Maxisorb) were coated with $100 \mu \mathrm{l}$ of $5 \mu \mathrm{g} / \mathrm{ml}$ PLA2 in buffered carbonate $(\mathrm{pH} 9.4)$ and incubated at $4{ }^{\circ} \mathrm{C}$ overnight. Plates were washed with PBS- $0.05 \%$ Tween 20 (PBST) and blocked with $150 \mu \mathrm{l}$ of $2.5 \%$ PBSTM for $1 \mathrm{~h}$. After washing, serial dilutions of individual sera in $100 \mu$ PBSTM were incubated in the plates for $2 \mathrm{~h}$. Subsequently, the plates were washed and incubated with $1 \mu \mathrm{g} / \mathrm{ml}$ biotinylated goat antimouse IgG1 or IgG2a in $100 \mu \mathrm{l}$ PBSTM for $2 \mathrm{~h}$. After washing and incubation with $100 \mu$ l of a 1:1,000 dilution of streptavidinconjugated horse-radish peroxidase for $1 \mathrm{~h}$, the plates were washed and developed with $100 \mu$ l enzyme substrate 2,2 '-azinobis(3-ethylbenzothiazoline-6-sulphonic acid) diammonium salt (Sigma-Aldrich) in $1 \mathrm{M}$ sodium dihydrogen phosphate. After $20 \mathrm{~min}$, the endpoint absorption was measured at $405 \mathrm{~nm}$.

For detection of specific IgE antibodies, plates were coated with $2 \mu \mathrm{g} / \mathrm{ml}$ of anti-mouse IgE capture antibody. As secondary reagent for binding to mouse serum, an in-house biotinylated PLA2 was used at $3 \mu \mathrm{g} / \mathrm{ml}$. Unless specified, all antibodies were from BD Biosciences Pharmingen, and all incubations were done at room temperature.

\section{RESULTS}

\section{Microparticle Characterization}

Three different PLGA formulations were prepared by a recently developed microextrusion based process $(12,15)$. The size of the particles increased slightly depending on the number of encapsulated components (Table 1). While $50 \%$ of the MP-PLA2-CpG-protamine particles were smaller than $8.2 \mu \mathrm{m}$, half the MP-PLA2 particles were smaller than a 4.41 $\mu \mathrm{m}$. The $90 \%$ cumulative undersize values were comparable for all tested formulations, i.e., 20.1 (MP-PLA2-CpG) to 26.3 (MP-PLA2-CpG-protamine) micrometers. The re-suspension

Table I. Zeta Potential and PLA2 Content of the Tested Microparticle (MP) Preparations

\begin{tabular}{lclcr}
\hline & $\begin{array}{l}\text { Size Distribution } \\
(\mu \mathrm{m}) \mathrm{D}_{10} / \mathrm{D}_{50} / \mathrm{D}_{90}\end{array}$ & $\begin{array}{l}\text { Zeta Potential }(\mathrm{mV}) \\
\text { w/o or w/ Lecithin }\end{array}$ & $\begin{array}{l}\text { PLA2 Content } \\
(\mu \mathrm{g} / \mathrm{mg} \text { MP) }\end{array}$ & $\begin{array}{l}\text { PLA2 Loading } \\
\text { Efficiency }(\%)\end{array}$ \\
\hline MP-PLA2 & $1.2 / 4.4 / 24.9$ & $-7.3 \pm 0.3,-12.3 \pm 1.6$ & 0.84 & 29 \\
MP-PLA2+CpG & $1.2 / 4.4 / 24.9$ & $-7.3 \pm 0.5,-9.7 \pm 0.5$ & 0.84 & 29 \\
MP-PLA2-CpG & $1.3 / 5.6 / 20.1$ & $-9.1 \pm 1.8,-12.5 \pm 0.9$ & 1.55 & 33 \\
MP-PLA2-CpG-protamine & $2.4 / 8.2 / 26.3$ & $-9.6 \pm 1.8,-13.7 \pm 1.6$ & 0.95 & 22 \\
\hline
\end{tabular}

The MP-PLA2+CpG corresponds to the MP-PLA2 preparation, but contains CpG that was admixed prior to injection; therefore, the PLA2 content of the two preparations are the same. The particle size distribution is indicated as $\mathrm{D}_{10}, \mathrm{D}_{50}$ and $\mathrm{D}_{90}$ cumulative undersizes 


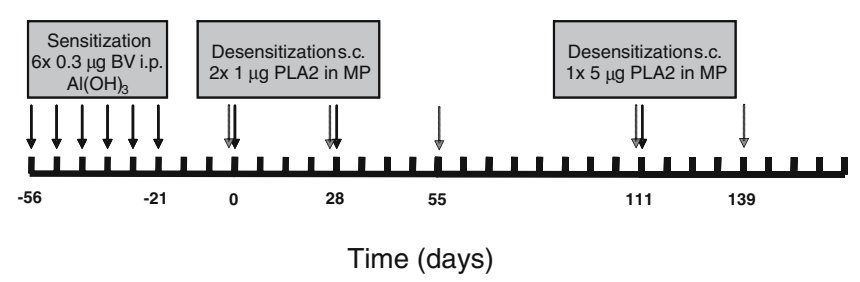

Fig. 1. Schematic illustration of the therapeutic immunization protocol. Black arrows represent injections and grey arrows represent bleedings.

of the particles in $1 \%$ lecithin resulted in an apparent decrease in size of the MP-PLA2-CpG formulation but not for the other formulations (not shown).

The zeta potential of all MP formulations was negative and changed only marginally upon admixture of $\mathrm{CpG}$ (from -7.5 $\mathrm{mV}$ for MP-PLA2 to $-7.3 \mathrm{mV}$ for MP-PLA2 + CpG), or upon co-encapsulation of $\mathrm{CpG}(-9.5 \mathrm{mV}$ for MP-PLA2-CpG), or else upon co-encapsulation of both $\mathrm{CpG}$ and protamine $(-9.6$ $\mathrm{mV}$ for MP-PLA2-CpG-protamine; Table 1). When the particles were re-suspended in lecithin, the zeta potentials decreased significantly in all formulations $(p<0.01$; un-paired, two-sided Student's $t$ test).

The experimentally determined PLA2 content in the MP ranged from $0.84 \mu \mathrm{g} / \mathrm{mg}$ (MP-PLA2) to $1.55 \mu \mathrm{g} / \mathrm{mg}$ (MPPLA2-CpG; Table 1). The corresponding microencapsulation efficiencies were in the range of 22 to $33 \%$.

The analysis of extracted PLA2 from the different MP formulations by SDS-PAGE produced a unique band for PLA2 at $16 \mathrm{kDa}$ (Fig. 2), which does not suggest any cleavage of the allergen during preparation and storage (6-12 months) of the MP. Furthermore, extracted PLA2 maintained its antigenicity as confirmed by inhibition ELISA with a polyclonal human antiserum (data not shown), suggesting that the protein structure remained intact during the MP preparation and storage.

The in vitro release of PLA2 from all formulations was triphasic and followed the same pattern (Fig. 3). An initial burst release during the first $24 \mathrm{~h}$ was followed by a dormant period over 2 weeks and a second release phase lasting more than seven weeks. While the release of PLA2 from the protamine-containing formulation was complete over this time period, the release from the protamine- and $\mathrm{CpG}$-free formulation (MP-PLA2) reached only $63 \%$.

\section{Immunogenicity}

We first determined the dose of microencapsulated PLA2 required to induce a specific immune response in mice after subcutaneous administration of two different PLGA MP preparations. Mice were immunized with 1 or $5 \mu \mathrm{g}$ of microencapsulated PLA2 in MP-PLA2 or MP-PLA2-CpG-protamine and boosted 28 days later with the same doses. As a control, one group of mice was primed and boosted with $1 \mu \mathrm{g}$ PLA2 adsorbed on aluminum hydroxide. As illustrated in Fig. 4, $5 \mu \mathrm{g}$ PLA2 in MS-PLA2 induced high levels of IgG1 while the $1 \mu \mathrm{g}$ PLA2 dose induced only weak IgG1 responses and no detectable IgG2a antibodies. The $\mathrm{CpG}$ - and protaminecontaining particles were strongly immunogenic for both IgG1 and IgG2a induction both at 1 and $5 \mu \mathrm{g}$ PLA2, and a single administration was sufficient for seroconversion in the latter group. Aluminum-adsorbed PLA2 induced only IgG1 antibodies and boosting was required.

Based on these results, we tested the immunogenicity of four different PLGA MP preparations containing $1 \mu \mathrm{g}$ of PLA2 (Table 1). Mice received two injections 28 days apart, and the PLA2-specific antibodies were measured 28, 55 and 84 days after the first injection. In line with the results above, a single administration of the $\mathrm{CpG}$-free formulation (MPPLA2) induced little or no detectable anti-PLA2 antibodies by day 28 (Fig. 5). At this time point, only the formulation MP-PLA2-CpG-protamine induced some IgG1, but no IgG2a antibodies. A second injection on day 28 did not notably increase the antibody titers of mice that had received MP-PLA2, unless CpG was admixed prior to injection (MPPLA2 + CpG). The co-encapsulation of CpG (MP-PLA2$\mathrm{CpG}$ ) further increased this response, which was additionally enhanced when both $\mathrm{CpG}$ and protamine were co-encapsulated (MP-PLA2-CpG-protamine). Maximum antibody titers for both $\mathrm{IgG}$ subclasses were observed 1 month after the second injection (day 55), after which time the antibody levels slightly decreased or remained stable during the next month (day 84). The IgG2a levels induced by the two MP preparations with encapsulated $\mathrm{CpG}$ (MP-PLA2-CpG and MPPLA2-CpG-protamine), but not with admixed CpG (MP-

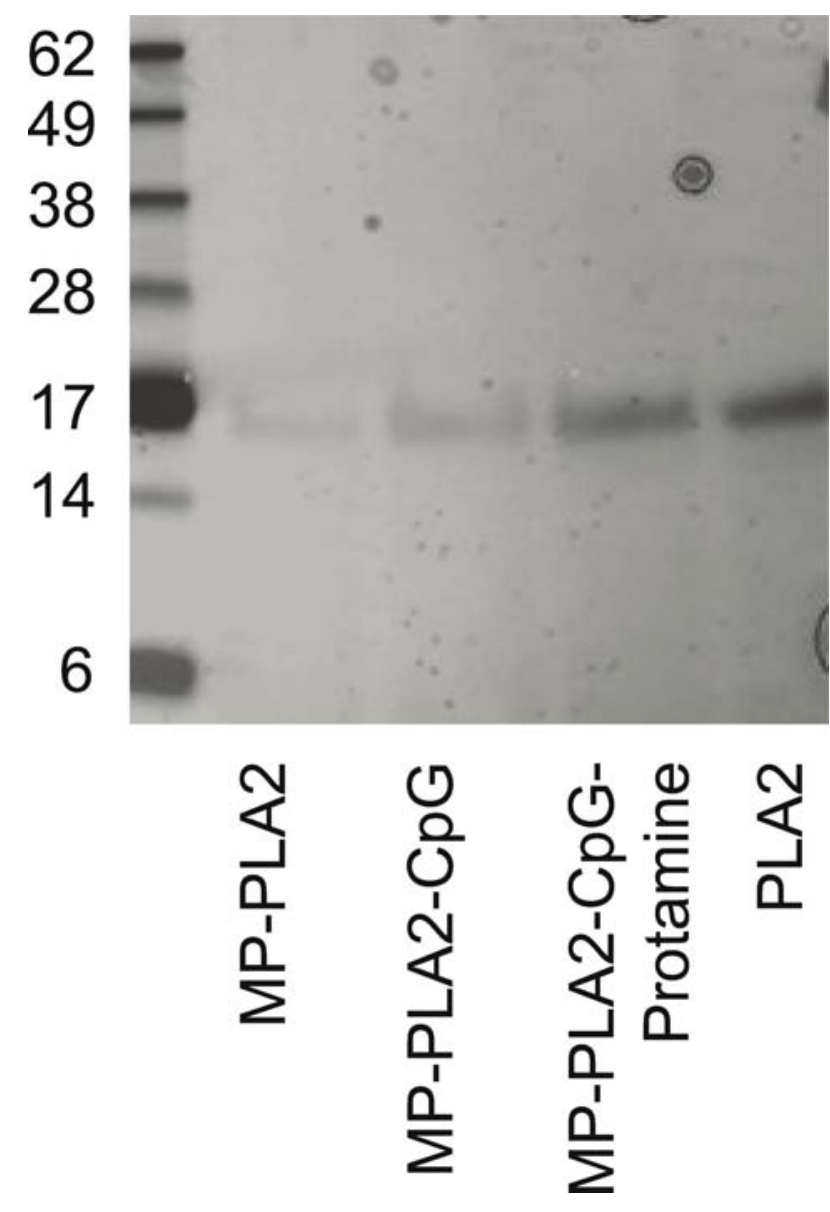

Fig. 2. Silver-stained SDS-PAGE of PLA2 extracted from the different microparticle formulations. First lane was loaded with Seeblue Plus marker and the last lane with $1 \mu \mathrm{g}$ of purified PLA2 as a positive control. For all the other lanes, maximal loading volumes were used. 


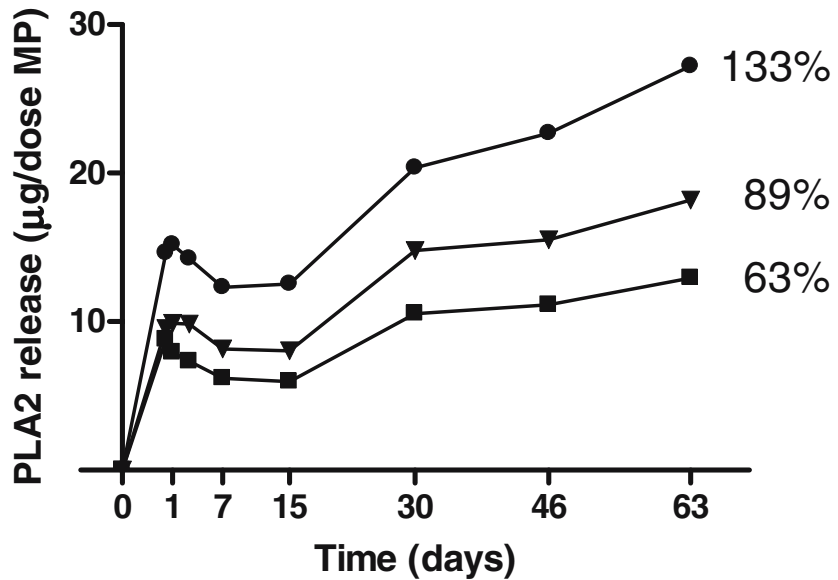

Fig. 3. Allergen in vitro release profile of the different MP formulations. PLA2 release at different time points as measured by inhibition ELISA and expressed in microgram per dose of MP used for the experiment and total release in percentage. MP-PLA2 (squares), MP$\mathrm{PLA} 2-\mathrm{CpG}$ (inverted triangle) and MP-PLA2-CpG-protamine (circles).

PLA2 + CpG), were significantly higher than those induced by PLA2 adsorbed on aluminum hydroxide $(p<0.05$ for the MPPLA2-CpG and $p<0.001$ for the MP-PLA2-CpG-protamine, as analyzed by a two-way ANOVA with Bonferroni posttest). Also, the quality of the total immune response was different between the immunogenic PLGA preparations and the aluminum adsorbed control vaccine. The latter induced an IgG1 (Th2) polarized antibody response, while the particles shifted the response towards an IgG2a (Th1), as evident from the IgG2a-to-IgG1 ratios (Fig. 5c). Neither the PLGA preparations nor the control group (aluminum hydroxide) induced detectable PLA2-specific IgE antibodies (data not shown).

\section{Allergen-specific Immunotherapy}

To evaluate the therapeutic potential of the different MP formulations, we used a murine anaphylaxis model. Mice were sensitized by six weekly intraperitoneal injections of bee venom allergen extract adsorbed on aluminum hydroxide. Three weeks after the last sensitization injection, SIT was initiated by subcutaneous injections with different PLGA formulations containing $1 \mu \mathrm{g}$ PLA2 or with $5 \mu \mathrm{g}$ PLA2 adsorbed on aluminum hydroxide (Fig. 1). As evident from Fig. 6a, two injections with $1 \mu \mathrm{g}$ of microencapsulated PLA2 were not sufficient to induce detectable titers of PLA2specific $\operatorname{IgG} 2 \mathrm{a}$ antibodies in the sensitized mice. Therefore, the animals were boosted at day 111 after the first SIT injection with the same MP preparations, but at the higher dose of $5 \mu \mathrm{g}$ PLA2. This increased the levels of allergenspecific IgG2a significantly compared to the pre-boosting titers. The two formulations with encapsulated $\mathrm{CpG}$ induced significantly stronger $(p<0.05$, as analyzed by a two-way ANOVA with Bonferroni posttest) IgG2a responses than those induced by the control vaccine with aluminum hydroxide. Finally, to assess the functional efficacy of the different treatments, mice were challenged with a high dose of PLA2, and their body temperature monitored before and after the challenge. Mice treated with MP containing $\mathrm{CpG}$ had the smallest body temperature drop (Fig. 6b), being significantly lower than that observed in the untreated control group $(p<0.05$ for MP-PLA2-CpG and $p<0.01$ for MP-PLA2-CpGprotamine, as analyzed by a one-way ANOVA with Dunnet's Multiple comparison test). In fact, IgG2a responses correlated with protection against anaphylaxis $(p=0.02$, correlation analyzed by the Pearson test). The higher the $\mathrm{IgG} 2 \mathrm{a}$ titers, the lower the temperature drop (Fig. 6c).

The levels of bee-venom specific of $\mathrm{IgE}$ and $\mathrm{IgG} 1$ increased similarly for all groups during the sensitization period and remained unchanged during SIT. For all groups, PLA2-specific IgG1 increased comparably during both sensitization and SIT (data not shown).

\section{DISCUSSION}

Allergen-specific immunotherapy (SIT) aims to shift the balance between $\mathrm{Th} 2$ and Th1 responses in favor of the latter. The consequences are an increase in Th1-related
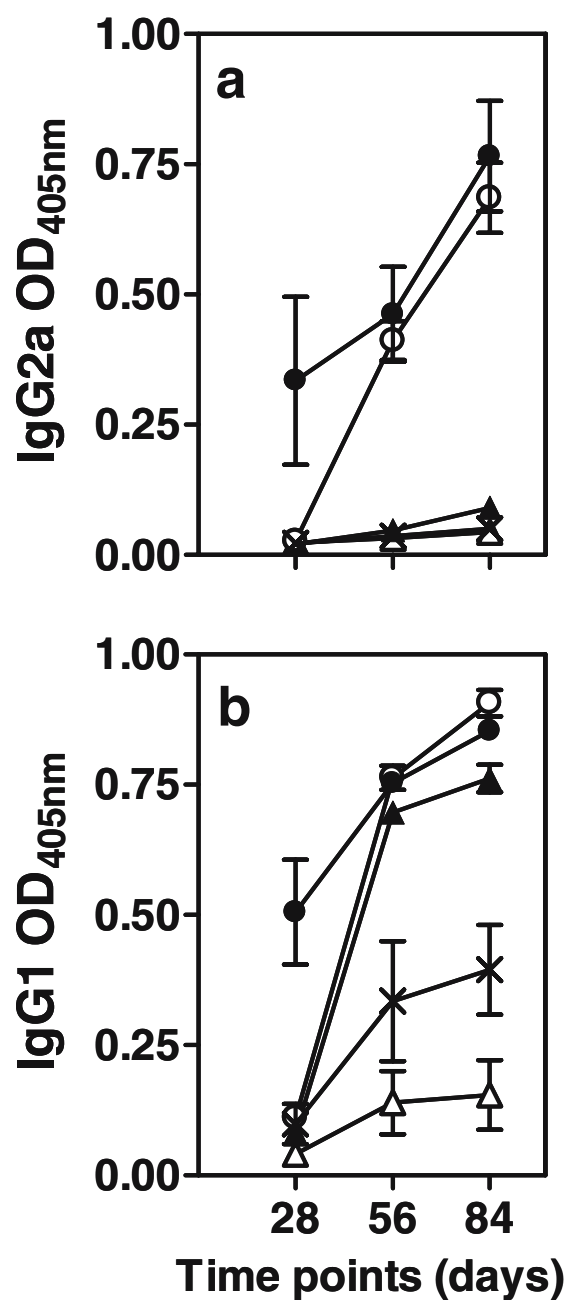

Fig. 4. Dose-dependant immunogenicity of PLA2-containing microparticles. Mice $(n=3)$ were immunized on days 0 and 28 with $1 \mu \mathrm{g}$ (empty symbols) or $5 \mu \mathrm{g}$ (filled symbols) of PLA2 contained in MPPLA2 (triangles), MP-PLA2-CpG-protamine (circles), or with $1 \mu \mathrm{g}$ of PLA2 adsorbed on $\mathrm{Al}(\mathrm{OH})_{3}$ (crosses). The sera were obtained at days 28, 56 and 84 and analyzed by ELISA for anti-PLA2 IgG2a (a) and IgG1 (b). The absorbances at 1/160 serum dilution were chosen as representative for each time point. 

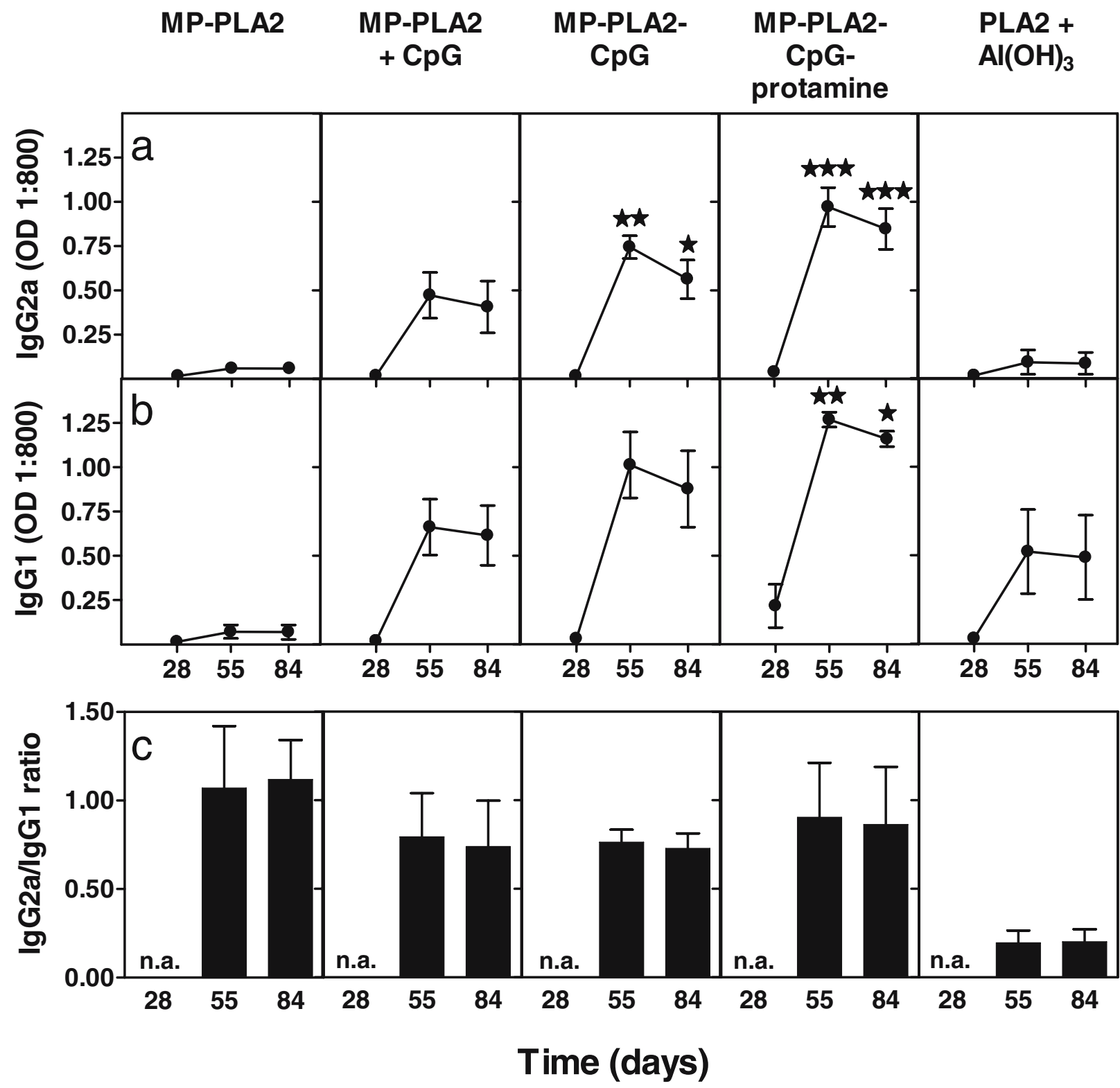

Fig. 5. Isotype profiles of anti-PLA2 serum antibodies. CBA/J mice were vaccinated on days 0 and 28 with $1 \mu \mathrm{g}$ PLA2 in different microparticle formulations, as indicated, or adsorbed on aliminum hydroxide as reference $(n=4)$. Blood was collected at days 28,55 and 84 and the sera analyzed by ELISA for anti-PLA2 IgG2a (a) IgG1 (b). Ratio of IgG2a to IgG1 was calculated at 1/800 serum dilution and only values above seroconversion (absorbance higher or equal that than of a negative serum plus three standard deviations) are plotted (c). Data were analyzed by a 2-way ANOVA with Bonferroni posttest. Significant differences are indicated as compared to the control group $(* * * p<0.001 ; * * p<0.01 ; * p<0.05)$.

antibodies ( $\mathrm{IgG} 4$ in humans, IgG2a in mice) and cytokines (IFN- $\gamma)(16,17)$, a reduction in Th2-associated IgE and IL-4 (18), and an increase in allergen-specific suppressive activity through regulatory CD25-positive CD4 T cells and IL-10 (19, 20). However, current SIT is costly and requires years of allergen injections. As the allergen dose cannot be increased due to allergic side effects, concepts to enhance the efficacy of SIT have focused on creating recombinant allergens with less allergic side effect or on the developing new adjuvants and delivery systems. So far, only adjuvants based on aluminum and calcium salts have been approved for SIT. Both compounds preferentially stimulated Th2-polarized antibody responses (21), but $\mathrm{T}$ cell responses were poor.
Biodegradable and biocompatible polymeric MP are particularly interesting candidates for allergy vaccines, because they release proteins over prolonged periods of time (22) and, thereby, reduce the need for frequent booster injections. Since entrapped allergen would be less accessible for binding $\mathrm{IgE}$ on the surface of mast cells and basophils, the encapsulation of allergens may also protect the allergic patient from undesired allergic side effects. Due to their particulate nature and small size, MP also have intrinsic adjuvant properties and may be combined with immunostimulatory agents to trigger distinct pathways of immunological reactions.

Oligodeoxynucleotides rich in cytosine-guanine immunostimulatory sequences $(\mathrm{CpG})$ are prototypes of $\mathrm{Th} 1$ 
a

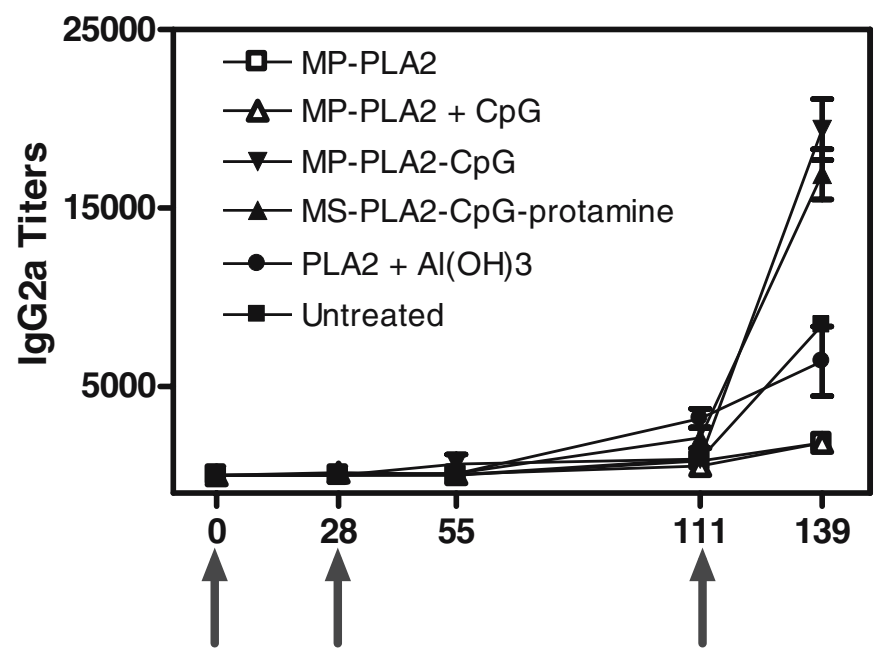

Time (days)
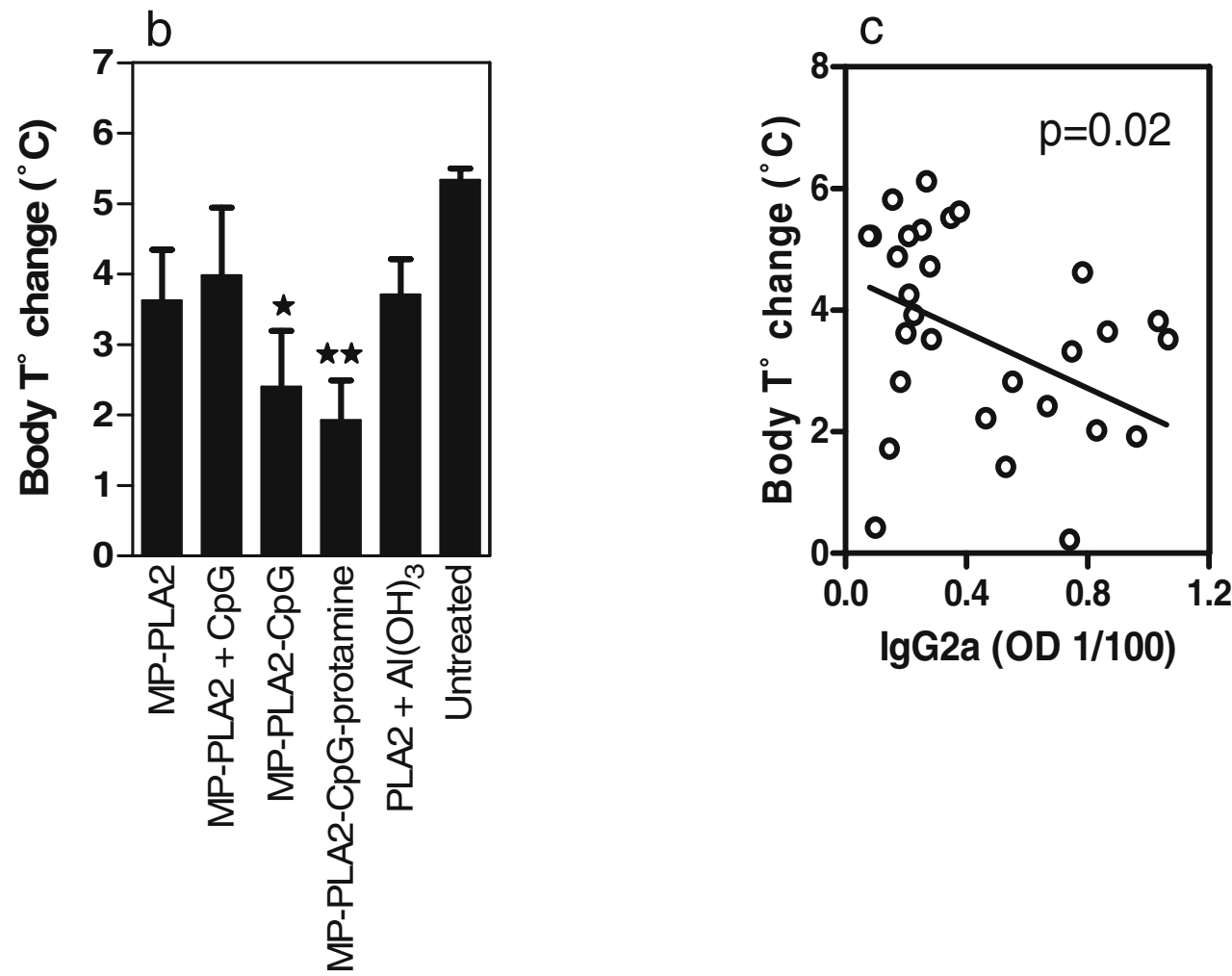

Fig. 6. Therapeutic potential of PLA2-containing microparticles. a Sensitized mice as described in the "Materials and methods" were therapeutically vaccinated with MP-PLA2 (empty squares), MP-PLA2 + CpG (empty triangles), MP-PLA2-CpG (filled inverted triangles), MP-PLA2-CpG-protamine (filled triangles), $\mathrm{PLA} 2$ adsorbed on $\mathrm{Al}(\mathrm{OH})_{3}$ (filled circles), or left untreated (filled squares). IgG2a titers were defined as the inverse of the highest dilution reaching an absorbance equal or higher than that of a negative serum plus three standard deviations and expressed as geometric means \pm standard error $(n=5)$. Similar levels of IgG1 and IgE were seen for all groups treated (not shown). b Induction of anaphylaxis responses against PLA2 in desensitized mice. After desensitization, the mice were challenged with $15 \mu \mathrm{g}$ of purified PLA2, and the body temperature was measured before and $30 \mathrm{~min}$ after the challenge. Values are expressed as body temperature difference before and after. Significant differences are indicated as compare to the untreated group $(* * p<0.01 ; * p<0.05)$. c Correlation between the level of protective antibodies and body temperature change. The $\operatorname{IgG} 2 \mathrm{a}$ absorbance from the last time point was plotted versus the body temperature change in challenged mice. The correlation was analyzed by the Pearson test, which assumes that the data is sampled from a Gaussian population, with a $95 \%$ confidence interval. 
response inducers. CpG stimulates TLR9 on APCs (23). It has been shown that $\mathrm{CpG}$ can restore imbalanced Th2-Th1 responses in allergic mice $(24,25)$, and that the conjugation of a ragweed allergen to $\mathrm{CpG}$ improved the therapeutic efficacy in patients with allergic rhinitis (26). In the present study, therefore, we combined $\mathrm{CpG}$ with allergen-containing PLGA MP and evaluated the immunogenicity and therapeutic potential of the formulations in a murine model of allergy.

The results suggested that co-encapsulation of allergen and $\mathrm{CpG}$ in PLGA MP can have important benefits for application in SIT. CpG lowered the dose-threshold for induction of allergen-specific immune responses. This paralleled a study that showed that PLGA MP containing a streptococcus antigen and $\mathrm{CpG}$ elicited significantly higher antigen-specific antibody responses when compared with the same vaccine without $\mathrm{CpG}$ (27). Moreover, only CpGcontaining preparations induced $\mathrm{IgG} 2 \mathrm{a}$ antibodies, suggesting that a potent allergy vaccine based on PLGA MP should also contain $\mathrm{CpG}$ or an equivalent Th1-triggering adjuvant. The therapeutic model confirmed this finding, by showing that CpG-containing MP preparations protected mice against induced anaphylaxis better than $\mathrm{CpG}$-free preparations.

Despite this clear adjuvant effect of $\mathrm{CpG}$, oligodeoxynucleotides have relatively short half-lifes in vivo due to degradation by nucleases $(28,29)$. For in vivo use, therefore, they have been stabilized by phosphorothioate-modification of the oligodeoxynucleotide backbone $(28,30)$. Alternatively, $\mathrm{CpG}$ has been conjugated to stabilizing compounds $(31,32)$ or packaged into virus-like particles (33). For the same purpose, we tested whether the PLGA MP-based allergy vaccine could be further improved by adding protamine to the formulation, as a putative stabilizer for DNA. The experiments revealed that the immunogenicity of the vaccine was indeed further enhanced when protamine was co-encapsulated. The induction of both $\operatorname{IgG} 1$ and $\operatorname{IgG} 2 \mathrm{a}$ isotypes increased, with a slightly stronger increase of the latter isotype. This resulted in better protection against anaphylaxis, as compared to all other PLA2 vaccine preparations tested.

Protamine is a cationic polypeptide that is known to stabilize DNA in the haploid phase of spermatogenesis. Pharmaceutically, it has been used to preserve plasmid DNA for gene transfer (34) and to avoid degradation of oligodeoxynucleotides (35). Besides direct stabilization of $\mathrm{CpG}$, the improved performance of the protamine-containing formulations could also be a secondary result of more efficient encapsulation of $\mathrm{CpG}$ due to complexation with protamine. Indeed, $\mathrm{CpG}$ adsorption was found to be stronger on protamine-containing particles than on protamine-free particles and the release of $\mathrm{CpG}$ was strongly sustained with the former particles (Fischer, unpublished data). Moreover, due to the neutralization of the negative charges on $\mathrm{CpG}$ by the positive protamine as well as the increased size of the protamine-CpG complex, the complex is expected to have a higher affinity for the polymer matrix than $\mathrm{CpG}$ alone. This should allow a more delayed release of the $\mathrm{CpG}$, which again would allow $\mathrm{CpG}$ and the allergen to reach the same APCs. Such a synchronized delivery of danger signals (adjuvant; so-called signal 0 and 2) and allergen (so-called signal 1 ) is one important criterion for optimal stimulation of longlasting immune responses (36). The importance of such synchronized allergen and $\mathrm{CpG}$ delivery was further underlined by the fact that admixed $\mathrm{CpG}$, released by a faster kinetics than the encapsulated allergen, induced weaker antibody responses and less protection than co-encapsulated allergen and $\mathrm{CpG}$. Experiments with MP formulations that contained co-encapsulated PLA2 and protamine, but no $\mathrm{CpG}$, performed similarly to the MP-PLA2 formulation (results not shown). This implies that co-encapsulated protamine exerted its effect through stabilization and improved encapsulation of $\mathrm{CpG}$ and not due to a direct immune regulatory or stimulatory effect.

One of the major concerns about encapsulation of therapeutic proteins and antigens is the risk of degradation or structural changes during the process. This has so far limited the clinical use of MP. In our study, the encapsulation of PLA2 did not seem to affect its integrity or immunogenicity. Nonetheless, some disruption of the molecule may not be as damaging for allergens as it may for other proteins. In fact, many of the new approaches in allergy treatment use modified allergens with low $\operatorname{IgE}$ binding capacity, e.g., recombinant proteins $(37,38)$, chemically crosslinked (39) or heat-denaturated allergens $(40,41)$.

To the best of our knowledge, this is the first report where the potential of PLGA MP with co-encapsulated allergen and $\mathrm{CpG}$ has been studied in vivo for use in allergen-specific immunotherapy. The preparations were strongly immunogenic in mice and the Th1-triggering effect of $\mathrm{CpG}$ was further improved by co-encapsulation of protamine. Importantly, this correlated with a better protection against anaphylaxis in bee venom allergic mice. Therefore, due to the increased efficacy and the reduced risk of allergic side effects, CpG- and allergen-containing PLGA MP represent a most attractive strategy for improving the conventional long-lasting and costly SIT.

\section{ACKNOWLEDGEMENTS}

The authors thank Mrs. María J. Pena Rodríguez for help with ELISA measurements, Mrs. Nathalie Schlegel and Dr. Nicole Graf for English editions, and Prof. Adriano Aguzzi for helpful discussions.

\section{REFERENCES}

1. C. Alexander, A. B. Kay, and M. Larche. Peptide-based vaccines in the treatment of specific allergy. Curr. Drug Targets Inflamm. Allergy 1:353-361 (2002).

2. F. Kussebi, F. Karamloo, C. Rhyner, P. Schmid-Grendelmeier, M. Salagianni, C. Mannhart, M. Akdis, L. Soldatova, Z. Markovic-Housley, B. R. Von Beust, T. Kundig, D. M. Kemeny, K. Blaser, R. Crameri, and C. A. Akdis. A major allergen genefusion protein for potential usage in allergen-specific immunotherapy. J. Allergy Clin. Immunol. 115:323-329 (2005).

3. M. Larche. Anti-T-cell strategies in the treatment of allergic disease. Allergy 57 Suppl 72:20-23 (2002).

4. S. R. Durham, S. M. Walker, E. M. Varga, M. R. Jacobson, F. O'Brien, W. Noble, S. J. Till, Q. A. Hamid, and K. T. NouriAria. Long-term clinical efficacy of grass-pollen immunotherapy. N. Engl. J. Med. 341:468-475 (1999).

5. A. W. Wheeler, and S. R. Woroniecki. Immunological adjuvants in allergy vaccines: Past, present and future. Allergol. Intern. 50:295-301 (2001).

6. S. Jilek, E. Walter, H. P. Merkle, and B. Corthesy. Modulation of allergic responses in mice by using biodegradable poly(lactideco-glycolide) microspheres. J. Allergy Clin. Immunol. 114:943950 (2004) 
7. M. Peyre, R. Audran, F. Estevez, G. Corradin, B. Gander, D. Sesardic, and P. Johansen. Childhood and malaria vaccines combined in biodegradable microspheres produce immunity with synergistic interactions. J. Control. Release 99:345-355 (2004).

8. M. Peyre, D. Sesardic, H. P. Merkle, B. Gander, and P. Johansen. An experimental divalent vaccine based on biodegradable microspheres induces protective immunity against tetanus and diphtheria. J. Pharm. Sci. 92:957-966 (2003).

9. S. Akira and S.Sato. Toll-like receptors and their signaling mechanisms. Scand J. Infect. Dis. 35:555-562 (2003).

10. A. M. Krieg. CpG motives in bacterial DNA and their immune effects. Annu. Rev. Immunol. 20:709-760 (2002).

11. A. M. Krieg, A.-K. Yi, S. Matson, T. J. Waldschmidt, G. A. Bishop, R. Teasdale, G. A. Koretzky, and D. M. Klinman. CpG motifs in bacterial DNA trigger direct B-cell activation. Nature 374:546 (1995)

12. S. Freitas, A. Walz, H. P. Merkle, and B. Gander. Solvent extraction employing a static micromixer: a simple, robust and versatile technology for the microencapsulation of proteins. $J$. Microencapsul 20:67-85 (2003).

13. S. Gebrekidan, B. H. Woo, and P. P. DeLuca. Formulation and in vitro transfection efficiency of poly (D, L-lactide-co-glycolide) microspheres containing plasmid DNA for gene delivery. AAPS PharmSciTech 1:E28 (2000).

14. M. V.Nesterenko, M. Tilley, and S. J. Upton. A simple modification of Blum's silver stain method allows for 30 minute detection of proteins in polyacrylamide gels. J. Biochem. Biophys. Methods 28:239-242 (1994).

15. S. Fischer, C. Foerg, S. Ellenberger, H. P. Merkle, and B. Gander. One-step preparation of polyelectrolyte-coated PLGA microparticles and their functionalization with model ligands. $J$. Control. Release 111:135 (2006).

16. S. R. Durham, S. Ying, V. A. Varney, M. R. Jacobson, R. M. Sudderick, I. S. Mackay, A. B. Kay, and Q. A. Hamid. Grass pollen immunotherapy inhibits allergen-induced infiltration of CD4+ T lymphocytes and eosinophils in the nasal mucosa and increases the number of cells expressing messenger RNA for interferon-gamma. J. Allergy Clin. Immunol. 97:1356-1365 (1996).

17. K. Gehlhar, M.Schlaak, W.Becker, and A.Bufe. Monitoring allergen immunotherapy of pollen-allergic patients: the ratio of allergen-specific IgG4 to IgG1 correlates with clinical outcome. Clin. Exp. Allergy 29:497-506 (1999).

18. H. Secrist, C. J. Chelen, Y. Wen, J. D. Marshall, and D. T. Umetsu. Allergen immunotherapy decreases interleukin 4 production in CD4+ $\mathrm{T}$ cells from allergic individuals. J. Exp. Med. 178:2123-2130 (1993).

19. K. T. Nouri-Aria, P. A. Wachholz, J. N. Francis, M. R. Jacobson, S. M. Walker, L. K. Wilcock, S. Q. Staple, R. C. Aalberse, S. J. Till, and S. R. Durham. Grass pollen immunotherapy induces mucosal and peripheral IL-10 responses and blocking IgG activity. J. Immunol. 172:3252-3259 (2004).

20. S. J. Till, J. N. Francis, K. Nouri-Aria, and S. R. Durham. Mechanisms of immunotherapy. J. Allergy Clin. Immunol. 113:1025-1034 (2004)

21. J.Bousquet, R.Lockey, and H. J. Malling. Allergen immunotherapy: therapeutic vaccines for allergic diseases. A WHO position paper. J. Allergy Clin. Immunol. 102:558-562 (1998).

22. M. Ying, B. Gander, H. P. Merkle, and G. Corradin. Induction of sustained and elevated immune responses to weakly immunogenic synthetic malarial peptides by encapsulation in biodegradable polymer microspheres. Vaccine 14:1442 (1996)

23. H. Hemmi, O. Takeuchi, T. Kawai, T. Kaisho, S. Sato, H. Sanjo, M. Matsumoto, K. Hoshino, H. Wagner, K. Takeda, and S. Akira. A Toll-like receptor recognizes bacterial DNA. Nature 408:740 (2000).

24. B. Banerjee, K. J. Kelly, J. N. Fink, J. D. Henderson, Jr., N. K. Bansal, and V. P. Kurup. Modulation of airway inflammation by immunostimulatory $\mathrm{CpG}$ oligodeoxynucleotides in a murine model of allergic aspergillosis. Infect. Immun. 72:6087-6094 (2004).
25. P. Johansen, G. Senti, J. M. Martinez Gomez, T. Storni, B. R. von Beust, B. Wuthrich, A. Bot, and T. M. Kundig. Toll-like receptor ligands as adjuvants in allergen-specific immunotherapy. Clin. Exp. Allergy 35:1591-8159 (2005).

26. P. S. Creticos, J. T. Schroeder, R. G. Hamilton, S. L. BalcerWhaley, A. P. Khattignavong, R. Lindblad, H. Li, R. Coffman, V. Seyfert, J. J. Eiden, D. Broide, and the Immune Tolerance Network. Immunotherapy with a ragweed-toll-like receptor 9 agonist vaccine for allergic rhinitis. N. Engl. J. Med. 355:14451455 (2006)

27. S. K. Hunter, M. E. Andracki, and A. M. Krieg. Biodegradable microspheres containing group B Streptococcus vaccine: immune response in mice. Am. J. Obstet. Gynecol. 185:1174 (2001)

28. S. Agrawal, J. Temsamani, W. Galbraith, and J. Tang. Pharmacokinetics of antisense oligonucleotides. Clin. Pharmacokinet 28:7-16 (1995).

29. C. A. Farmanand, and D. J. Kornbrust. Oligodeoxynucleotide studies in primates: antisense and immune stimulatory indications. Toxicol. Pathol. 31 Suppl:119-122 (2003).

30. D. P. Sester, S. Naik, S. J. Beasley, D. A. Hume, and K. J. Stacey. Phosphorothioate backbone modification modulates macrophage activation by CpG DNA. J. Immunol. 165:4165-4173 (2000).

31. S. W. Lee, M. K. Song, K. H. Baek, Y. Park, J. K. Kim, C. H. Lee, H. K. Cheong, C. Cheong, and Y. C. Sung. Effects of a hexameric deoxyriboguanosine run conjugation into $\mathrm{CpG}$ oligodeoxynucleotides on their immunostimulatory potentials. J. Immunol. 165:3631-3639 (2000).

32. Y. Park, Y. S. Chang, S. W. Lee, S. Y. Cho, Y. K. Kim, K. U. Min, Y. Y. Kim, S. H. Cho, and Y. C. Sung. The enhanced effect of a hexameric deoxyriboguanosine run conjugation to $\mathrm{CpG}$ oligodeoxynucleotides on protection against allergic asthma. $J$. Allergy Clin. Immunol. 108:570-576 (2001).

33. T. Storni, C. Ruedl, K. Schwarz, R. A. Schwendener, W. A. Renner, and M. F. Bachmann. Nonmethylated CG motifs packaged into virus-like particles induce protective cytotoxic $\mathrm{T}$ cell responses in the absence of systemic side effects. J. Immunol. 172:1777-1785 (2004).

34. S. Liand, and L. Huang. In vivo gene transfer via intravenous administration of cationic lipid-protamine-DNA (LPD) complexes. Gene Ther. 4:891 (1997)

35. M. Gonzalez Ferreiro, R. M. Crooke, L. Tillman, G. Hardee, and R. Bodmeier. Stability of polycationic complexes of an antisense oligonucleotide in rat small intestine homogenates. Eur. J. Pharm. Biopharm. 55:19 (2003).

36. V. E. Schijns. Immunological concepts of vaccine adjuvant activity. Curr. Opin. Immunol. 12:456-463 (2000).

37. C. Wild, M. Wallner, K. Hufnagl, H. Fuchs, K. HoffmannSommergruber, H. Breiteneder, O. Scheiner, F. Ferreira, and U. Wiedermann. A recombinant allergen chimer as novel mucosal vaccine candidate for prevention of multi-sensitivities. Allergy 62:33-41 (2007)

38. R. Crameri, S. Flückiger, I. Daigle, T. M. Kündig, and C. Rhyner. Design, engineering, and in-vitro evaluation of MHC class II targeting allergy vaccines. Allergy 62:197-206 (2007).

39. J. Bousquet, A. Hejjaoui, M. Soussana, and F. B. Michel. Double-blind, placebo-controlled immunotherapy with mixed grasspollen allergoids. IV. Comparison of the safety and efficacy of two dosages of a high-molecular-weight allergoid. J. Allergy Clin. Immunol. 85:490-497 (1990).

40. M. J. Kim, J. W. Lee, H. S. Yook, S. Y. Lee, M. C. Kim, and M. W. Byun. Changes in the antigenic and immunoglobulin E-binding properties of hen's egg albumin with the combination of heat and gamma irradiation treatment. J. Food Prot 65:1192-1195 (2002)

41. P.Johansen, G.Senti, J. M. Martinez Gomez, B. Wuthrich, A. Bot, and T. M. Kundig. Heat denaturation, a simple method to improve the immunotherapeutic potential of allergens. Eur. J. Immunol. 35:3591-3598 (2005). 